\title{
Biermann, Ingrid, Von Differenz zu Gleichheit. Frauenbewegung und Inklusionspolitiken im 19. und 20. Jahrhundert
}

Paul Pasteur

\section{OpenEdition}

Édition électronique

URL : http://journals.openedition.org/ifha/2227

DOI : 10.4000/ifha.2227

ISSN : 2198-8943

\section{Éditeur}

IFRA - Institut franco-allemand (sciences historiques et sociales)

\section{Référence électronique}

Paul Pasteur, «Biermann, Ingrid, Von Differenz zu Gleichheit. Frauenbewegung und Inklusionspolitiken im 19. und 20. Jahrhundert», Revue de l'IFHA [En ligne], Date de recension, mis en ligne le 01 janvier 2010, consulté le 22 septembre 2020. URL : http://journals.openedition.org/ifha/2227 ; DOI : https://doi.org/ 10.4000/ifha. 2227

Ce document a été généré automatiquement le 22 septembre 2020.

(CIFHA 


\title{
Biermann, Ingrid, Von Differenz zu Gleichheit. Frauenbewegung und Inklusionspolitiken im 19. und 20. Jahrhundert
}

\author{
Paul Pasteur
}

1 La sociologue I.B. se propose d'étudier les combats politiques du premier et du nouveau mouvement des femmes et de montrer comment ces mouvements envisagent les notions de différence et d'égalité. Pour elle, les conceptions d'égalité, fondées au XIXe siècle sur la différence entre les sexes ou dans les années 1960-1970 sur le refus de cette même différence, déterminent les stratégies de mobilisation et de légitimation des mouvements de femmes.

2 Même si l'auteure mobilise souvent l'histoire, en résumant les travaux de collègues, cet ouvrage défend plus la séduisante mais vague idée résumée dans le titre qu'une thèse basée sur des exemples et faits concrets. On constate que l'auteure ne pointe jamais les différences entre les études réalisées au cours des années 1970 et celles publiées dans la dernière décennie, comme si l'histoire des femmes et du genre ne s'était pas forgée une historiographie complexe, comme si les études existaient en dehors de toute pression $\mathrm{du}$ temps et des mouvements. Pour défendre sa thèse, il arrive aussi fréquemment à l'auteure de mettre sur un même plan des textes du début du XXe siècle et des études réalisées depuis les années 1970.

3 Cet ouvrage déroutera les historiens et les historiennes francophones. La forme ellemême de l'ouvrage déconcerte : les deux premiers chapitres remplacent de facto une introduction absente, le dernier faisant office de conclusion. Dans le chapitre trois consacré à la " famille moderne " (die moderne Kleinfamilie) de 1860 à 1920, il est étonnant de ne voir apparaître la référence au code civil prussien de 1794 (ALR) qu'en p. 72 (soit 23 pages après le début du chapitre). Quant au code civil français et à son application dans les pays allemands, l'auteure semble considérer que cela reste sans conséquence sur les conceptions et représentations de la famille en Allemagne. La 
référence à l'exclusion des femmes de la vie publique par la Révolution française, réaffirmée dans l'espace germanique par les lois prussiennes de 1814, autrichiennes de 1867 , est elle tout simplement absente, ce qui lorsqu'on disserte sur « l'inclusion » des femmes dans la société est pour le moins problématique. Il n'est pas sûr que les pages consacrées aux différences entre les sexes et à la place des femmes dans la société " pré-moderne » ravissent plus les spécialistes et contribuent amplement au débat. De nombreux faits sont cités sans référence au contexte historique ou à la situation internationale : ainsi lorsqu'elle revient sur la création du cartel regroupant les organisations des femmes bourgeoises, le BDF, elle oublie ou ignore qu'il s'agissait alors de se fédérer au niveau international ; les transferts au sein de l'espace nord-atlantique pourtant déterminants dans le développement des mouvements de femmes, tant pour la réflexion théorique que pour les pratiques, ne sont présents qu'au travers de quelques textes concernant les mouvements féminins anglais présentés en annexe.

4 Si on peut défendre l'idée qu'il est nécessaire de souligner auprès des étudiant-e-s l'existence d'un premier mouvement des femmes et de l'opposer au second des années 1970, de très nombreuses études ont montré la permanence du mouvement des femmes dans les années vingt et les années trente. Les revendications d'égalité, les luttes pour le droit à l'avortement sous la République de Weimar ne se sont tues qu'en raison du triomphe du national-socialisme.

5 Enfin, pour un ouvrage rédigé à la fin de la première décennie du XXIe siècle, la question de la défense des bastions masculins, tels que les partis, les syndicats, les Églises ou l'armée, est elle aussi étonnement absente.

Paul Pasteur (Université de Rouen) 